\title{
Synthesis, Characterization, and Biological Activity of Nickel (II) and Palladium (II) Complex with Pyrrolidine Dithiocarbamate (PDTC)
}

\author{
Sk Imadul Islam, ${ }^{1}$ Suvendu Bikash Das, ${ }^{1}$ Sutapa Chakrabarty, ${ }^{1}$ Sudeshna Hazra, \\ Akhil Pandey, ${ }^{2}$ and Animesh Patra ${ }^{1}$ \\ ${ }^{1}$ Postgraduate Department of Chemistry, Midnapore College, Midnapore 721101, India \\ ${ }^{2}$ Department of Microbiology, Midnapore College, Midnapore 721101, India
}

Correspondence should be addressed to Animesh Patra; animeshpatrarl@yahoo.com

Received 25 April 2016; Revised 2 August 2016; Accepted 9 August 2016

Academic Editor: Ismail Warad

Copyright (C) 2016 Sk Imadul Islam et al. This is an open access article distributed under the Creative Commons Attribution License, which permits unrestricted use, distribution, and reproduction in any medium, provided the original work is properly cited.

The synthesis of square planar $\mathrm{Ni}(\mathrm{II})$ and $\mathrm{Pd}(\mathrm{II})$ complexes with pyrrolidine dithiocarbamate (PDTC) was characterized by elemental, physiochemical, and spectroscopic methods. Two complexes were prepared by the reaction of nickel acetate and palladium acetate with pyrrolidine dithiocarbamate (PDTC) in $1: 2$ molar ratio. The bovine serum albumin (BSA) interaction with complexes was examined by absorption and fluorescence spectroscopic techniques at $\mathrm{pH}$ 7.4. All the spectral data suggest that coordination of the pyrrolidine dithiocarbamate (PDTC) takes place through the two sulphur atoms in a symmetrical bidentate fashion. All the synthesized compounds were screened for their antimicrobial activity against some species of pathogenic bacteria (Escherichia coli, Vibrio cholerae, Streptococcus pneumonia, and Bacillus cereus). It has been observed that complexes have higher activity than the free ligand.

\section{Introduction}

The dithiocarbamate stoichiometry has much external consideration in recent years due to its ability to act as a bidentate ligand [1-3]. Dithiocarbamates such as diethyl dithiocarbamates and pyrrolidine dithiocarbamate display cytotoxic properties and they have been used to fight against metal poisoning [4-6]. The complexes are thermodynamically stable, so they are used as chelating agent for the extraction of trace metals [5, 7]. Metal complexes of dithiocarbamate present a wide range of applications in agriculture, medicine, industry, and analytical and organic chemistry [2,7]. The dithiocarbamate complexes are commercially important because they are used in rubber vulcanization process [8].

The metal complexes show enhanced biological activities such as antibacterial, antimalarial, and fungicidal activities compared to free ligands due to drop in polarity of metals after complexation $[9,10]$. Dithiocarbamates from nickel group that is of platinum (II) and palladium (II), as well as of isoelectronic gold (III), showed remarkable antitumor properties [11]. Particularly, nickel (II) and palladium (II) play an important role in both fundamental research and application of their physical properties. Nickel and palladium complex with pyrrolidine dithiocarbamate (PDTC) has been studied extensively.

Herein, we report an account of $\mathrm{Ni}$ and Pd (II) complex with formulae $\left[\mathrm{Ni}(\mathrm{PDTC})_{2}\right]$ and $\left[\mathrm{Pd}(\mathrm{PDTC})_{2}\right]$ synthesized. The BSA binding study of the complexes has been performed spectroscopically. The PDTC and its metal (II) complexes show antibacterial activities screened by disc diffusion method beside some variety of pathogenic bacteria.

\section{Experimental}

2.1. Materials and Physical Measurements. Nickel acetate and palladium acetate (E. Merck) were distilled before use. Solvents (methanol, ethanol, DMF, chloroform, etc.) were purified by standard methods. Ammonium dithiocarbamate 
TABLE 1: Elemental analysis of L (PDTC) and its complexes.

\begin{tabular}{lcccccccc}
\hline Formula & \multirow{2}{*}{ Comp. } & \multirow{2}{*}{ MW } & \multirow{2}{*}{ MP $\left({ }^{\circ} \mathrm{C}\right)$} & Colour & \multicolumn{4}{c}{ Found (calculated)\% } \\
& & & & & $\mathrm{C}$ & $\mathrm{H}$ & $\mathrm{N}$ \\
\hline $\mathrm{C}_{5} \mathrm{H}_{8} \mathrm{NS}_{2}$ & $\mathbf{L}$ & 164 & 144 & White & $36.58(36.64)$ & $4.87(4.95)$ & $8.53(8.59)$ \\
$\mathrm{C}_{10} \mathrm{H}_{16} \mathrm{~N}_{2} \mathrm{~S}_{4} \mathrm{Ni}$ & $\mathbf{1}$ & 350.69 & 268 & Light green & $34.21(34.42)$ & $4.56(4.73)$ & $7.92(7.96)$ & $16.73(16.84)$ \\
$\mathrm{C}_{10} \mathrm{H}_{16} \mathrm{~N}_{2} \mathrm{~S}_{4} \mathrm{Pd}$ & $\mathbf{2}$ & 398.42 & 308 & Yellow & $30.12(30.26)$ & $4.01(4.07)$ & $7.02(7.09)$ & $26.71(26.79)$ \\
\hline
\end{tabular}

(Aldrich) was used as received without further purification. The elemental $(\mathrm{C}, \mathrm{H}$, and $\mathrm{N})$ analyses were performed on a Perkin-Elmer model 2400 elemental analyzer. Nickel and palladium were analyzed by Varian atomic absorption spectrophotometer (AAS) model-AA55B, GTA using graphite furnace. Electronic absorption spectra were carried out on a SHIMADZU UV-1800 spectrophotometer. The fluorescence spectrum of albumin was obtained in the Fluorimeter (Hitachi-2000) with thermostat. IR spectra were recorded using a Perkin-Elmer FTIR model RX1 spectrometer. Molar conductance values $(\mu)$ were measured in systronics conductivity meter 304 model in DMF solvent. The concentrations of BSA were determined from optical density capacity, using the values of molar absorptivity of $\varepsilon 280=44720$ and $35700 \mathrm{M}^{-1} \mathrm{~cm}^{-1}$.

2.2. Preparation of $\left[\mathrm{Ni}(\mathrm{PDTC})_{2}\right]$ (1) and $\left[\mathrm{Pd}(\mathrm{PDTC})_{2}\right]$ (2). To prepare these complexes, $\mathbf{1}$ and $\mathbf{2}$, a common procedure was followed as described below, using nickel acetate for complex (1), palladium acetate for complex (2), and the organic ligand (HL) in stoichiometry ratio $(1: 2)$. A methanolic solution of L $(0.082 \mathrm{~g})$ was mixed with $0.07121 \mathrm{~g}$ of nickel acetate and $0.0561 \mathrm{~g}$ of palladium acetate with stirring condition and the mixture was refluxed for 3 hours. After the completion of the reaction, the reaction mixture was cooled down to room temperature and precipitate was filtered, dried, and recrystallized from methanol to give pure product.

2.3. BSA Binding Experiments. The BSA binding interactions between complexes were performed by absorption spectra and fluorometric titration in presence of phosphate buffer at $\mathrm{pH}$ 7.4. The aqueous solution of protein was titrated by addition of the proper concentration of the solution complexes. For every addition, the mixture solution was shaken and sanctioned to rise for 20 minutes, and then the fluorescence intensities were calculated with an excitation wavelength of $280 \mathrm{~nm}$.

2.4. Antimicrobial Screening. The antibacterial screening effects of the compounds were tested against four bacterial strains, namely, Escherichia coli, Vibrio cholerae, Streptococcus pneumoniae (Gram-negative bacteria), and Bacillus cereus (Gram-positive bacteria) $[12,13]$. The antibacterial activities of complexes 1 and $\mathbf{2}$ were done in DMF solvent. The solutions of ligand and complexes $\mathbf{1}$ and $\mathbf{2}$ were added to the agar plates. The DMF solvent was used as a negative control. Incubation of the plates was done at $37^{\circ} \mathrm{C}$ for 24 hours; inhibition of the organisms was measured and used to calculate mean of inhibition zones in millimetres.

2.5. Theoretical Methodology. The density functional theory (DFT) calculations were performed in the gas phase using the B3LYP (Becke three-parameter Lee-Yang-Parr) exchange correlation functional [14]. The basis set LanL2DZ was used to palladium (II) complex for all atoms. All calculations were approved using the GAUSSIAN 09 program with the support of the Gauss View visualization program [15].

\section{Results and Discussion}

3.1. Synthesis and Characterization of Complexes 1 and 2. The square planar nickel (II) and palladium (II) complex was obtained in good yield from the reaction of the metal acetate with organic moiety L (PDTC) in the methanol medium $(1: 2)$ ratio. The organic molecule $\mathbf{L}$ acts as bidentate ligand through $\mathrm{S}, \mathrm{S}$ - donor centres. The molar conductivity values for complexes 1 and $2\left(\Lambda \mathrm{o}, \mathrm{ohm}^{-1} \mathrm{~cm}^{2} \mathrm{~mol}^{-1}\right)$ are 48 and 52 at $300 \mathrm{~K}$, indicating that complexes are nonelectrolyte in DMF solution. The elemental analysis of $\mathbf{L}$ and complexes (given in Table 1) is reliable with the designed results from the empirical formula of each compound. All the complexes are air-stable, nonhygroscopic, partly soluble in ethanol and methanol, and soluble in acetonitrile, DMSO, and DMF and are monomeric in nature.

3.2. Infrared Spectra. The IR data of the ligand (Figure 1) pyrrolidine dithiocarbamate (PDTC) shows several bands at $1454,939,827$, and $2968 \mathrm{~cm}^{-1}$ due to C-N, C=S, C-S, and C-H bond stretching vibrations in the solid state, respectively [16]. These bands are shifted to lower frequency on complexation with different stoichiometry ratio. New vibrations at $428-$ $442 \mathrm{~cm}^{-1}$ for complexes 1 and 2 are not present in the free ligand. The new stretching frequency of $v(\mathrm{M}-\mathrm{S})$ bond in complexes 1 and 2 at $428 \mathrm{~cm}^{-1}$ and $442 \mathrm{~cm}^{-1}$ confirmed the involvement of only sulphur atom (Figures 2 and 3) in chelation with metal ions [17].

3.3. Electronic Absorption Spectral Study. At room temperature, electronic absorption spectra of PDTC and complexes (1 and 2) were recorded in DMF solvent (given in Figure 4). The spectra of the ligand (L) pyrrolidine dithiocarbamate exhibit main peaks: at $354 \mathrm{~nm}$. The peaks were attributed to $\pi \rightarrow \pi^{*}$ transitions, respectively [18]. The absorption spectra of the nickel (II) complex exhibit broad bands at $325 \mathrm{~nm}$ and $387 \mathrm{~nm}$ attributed to $\mathrm{n} \rightarrow \pi^{*}$ and $\pi \rightarrow \pi^{*}$ transition; again, the 


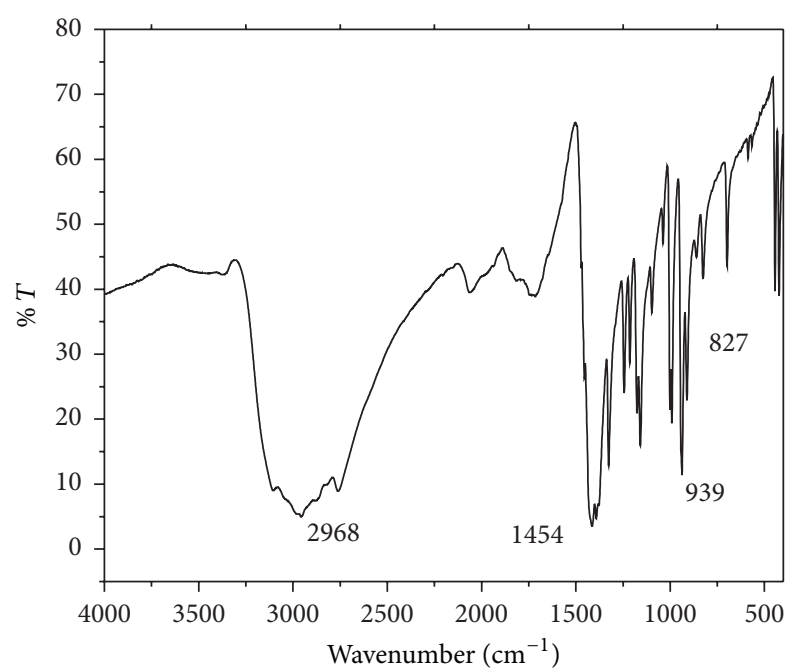

FIGURE 1: IR spectrum of ligand L (PDTC).

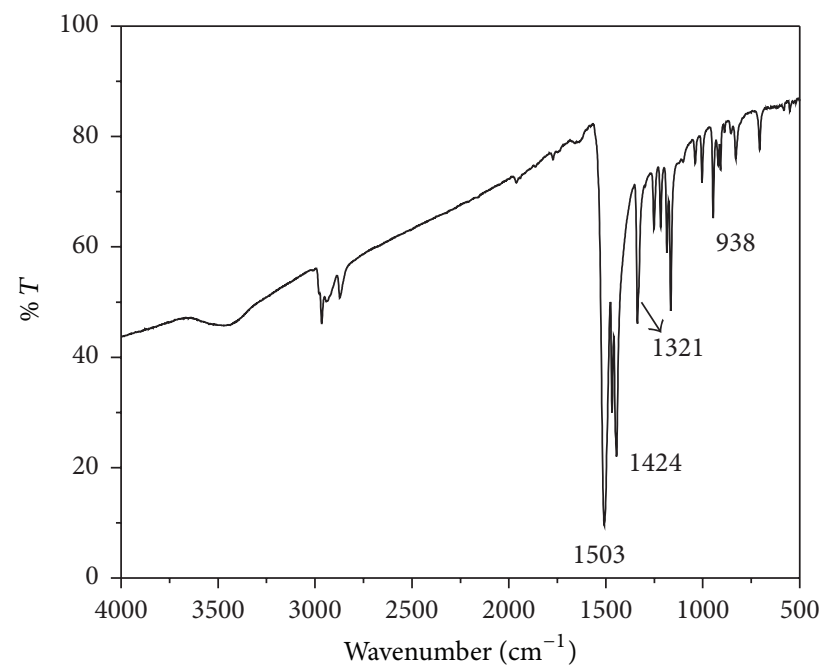

FIgURE 2: IR spectrum of $\left[\mathrm{Ni}(\mathrm{PDTC})_{2}\right]$ complex.

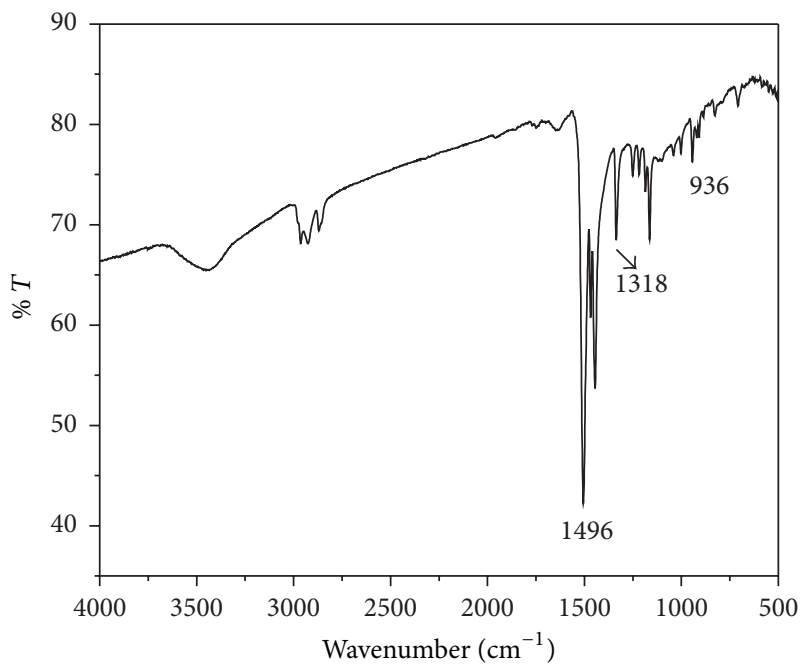

FIGURE 3: IR spectrum of $\left[\mathrm{Pd}(\mathrm{PDTC})_{2}\right]$ complex.

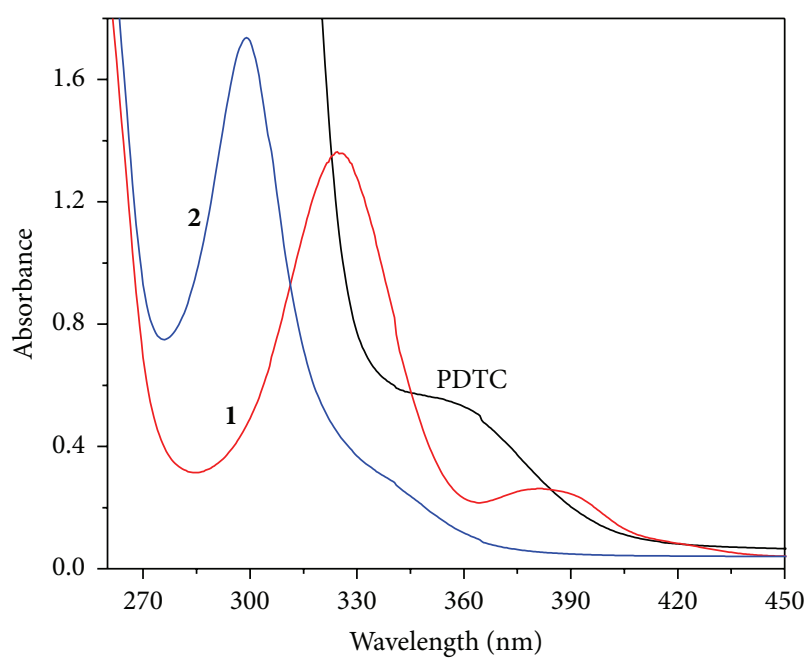

FIGURE 4: UV-Vis spectra of ligand (PDTC) and its corresponding complexes $\mathbf{1}$ and 2.

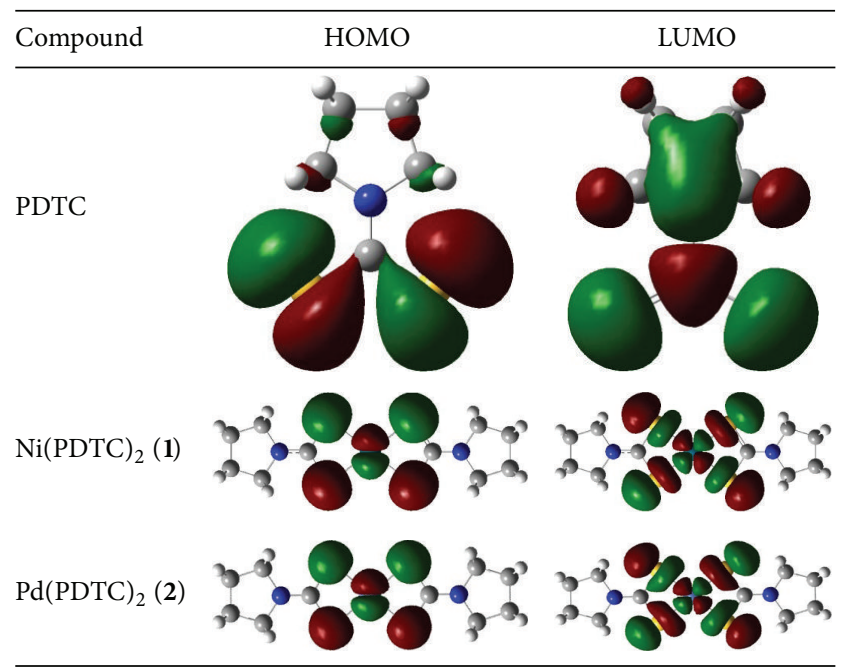

FIGURE 5: Some selected molecular orbitals of PDTC and its complexes $\mathbf{1}$ and 2 .

palladium (II) complex presents broad bands at $298 \mathrm{~nm}$ and $342 \mathrm{~nm}$ accredited to $\mathrm{n} \rightarrow \pi^{*}$ and $\pi \rightarrow \pi^{*}$ transition.

3.4. Electronic Structure. Full geometry optimization of $\mathbf{L}$ and its complexes was approved by density functional theory (DFT) at the B3LYP level in their ground state and the frontier orbitals of HOMO and LUMO of $\mathbf{L}$ and its complexes are given in Figure 5. Thus, it is inferred that in HOMO of $\mathbf{L}$ electrons are localised on C-S group but in complex electrons are localised on metal and C-S group. In LUMO, electrons are largely localized on pyrrole ring and $\mathrm{S}$ group. The HOMO-LUMO energy difference of PDTC in ground state is $0.16574 \mathrm{eV}$ but in complexes energy gap is $0.0211 \mathrm{eV}$ and $0.01919 \mathrm{eV}$ for $\mathbf{1}$ and $\mathbf{2}$, respectively. 


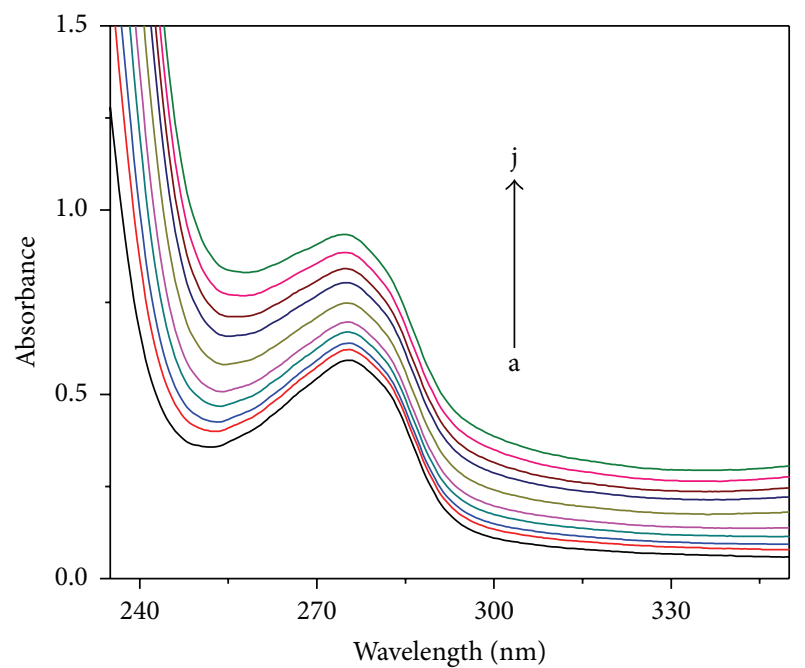

FIgURE 6: Absorption spectrum of nickel complex (1) with BSA at $280 \mathrm{~nm}$ in phosphate buffer. Arrow indicates increase of the concentration of complex (1).

\subsection{BSA Protein Binding Experiments}

3.5.1. Absorption Characteristics of BSA with Complexes 1 and 2. BSA gives absorption band at $280 \mathrm{~nm}$ due to the aromatic tryptophan and tyrosine residues. The absorption spectra of BSA in the absence and presence of complexes $\mathbf{1}$ and $\mathbf{2}$ were studied at different concentrations. We observed that absorption of BSA increases frequently upon increasing the concentration of the complex, indicating the formation of a ground state complex $[19,20]$. As dynamic quenching does not affect the absorption spectrum of quenching molecule, the observed changes in presence of complex could be indicating static quenching interaction between complex and serum albumin. The absorption spectra of BSA with complexes 1 and 2 are given in Figures 6 and 7. The apparent association constant $\left(K_{\text {app }}\right)$ determined the complex with BSA using the Benesi-Hildebrand equation [21]

$$
\frac{1}{\left(A_{\mathrm{obs}}-A_{0}\right)}=\frac{1}{\left(A_{c}-A_{0}\right)}+\frac{1}{K_{\mathrm{app}}\left(A_{c}-A_{0}\right)}[\mathrm{comp}]
$$

where $A_{\text {obs }}$ indicates observed absorbance of the solution having different concentrations of the complex at $280 \mathrm{~nm}$, $A_{0}$ is the absorbance of BSA, $A_{c}$ is the absorbances complex at $280 \mathrm{~nm}$, and $K_{\text {app }}$ represents the apparent association constant. The enrichment of absorbance at $280 \mathrm{~nm}$ was due to adsorption of the surface complex, based on the linear relationship between $1 /\left(A_{\mathrm{obs}}-A_{0}\right)$ and reciprocal concentration of the complex. The apparent association constant $\left(K_{\text {app }}\right)$ for complexes 1 and 2 was $3.18 \times 10^{4} \mathrm{M}^{-1}(R=0.9884)$ and 3.47 $\times 10^{4} \mathrm{M}^{-1}(R=0.9869)$ indicating complexes are strongly bound with BSA protein.

3.5.2. Fluorescence Quenching of BSA by Complexes 1 and 2. The emission spectra of BSA in presence of different concentrations of complexes $\mathbf{1}$ and $\mathbf{2}$ were recorded in the wavelength range $295-530 \mathrm{~nm}$ by exciting the protein at

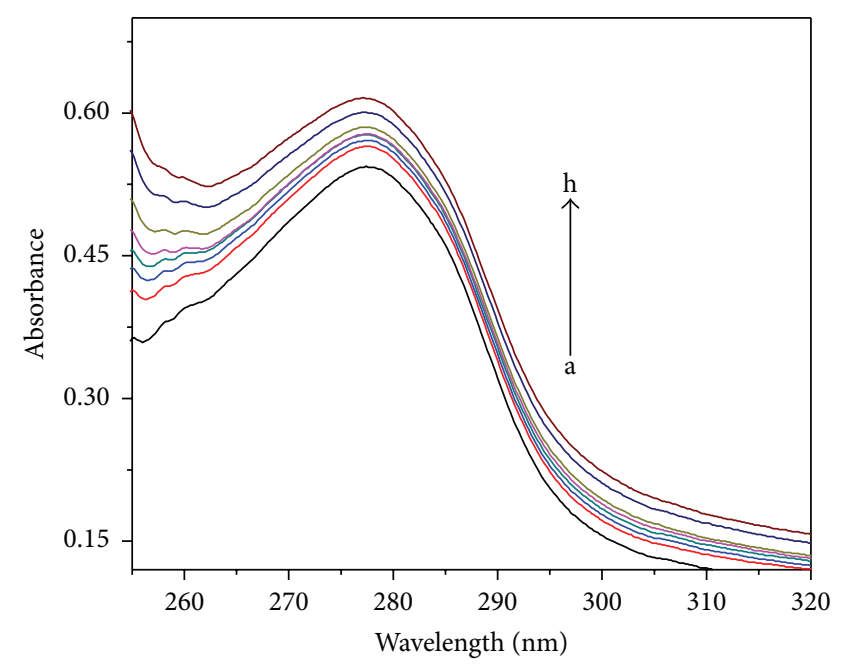

FIGURE 7: Absorption spectrum of palladium complex (2) with BSA at $280 \mathrm{~nm}$ in phosphate buffer. Arrow indicates increase of the concentration of complex (2).

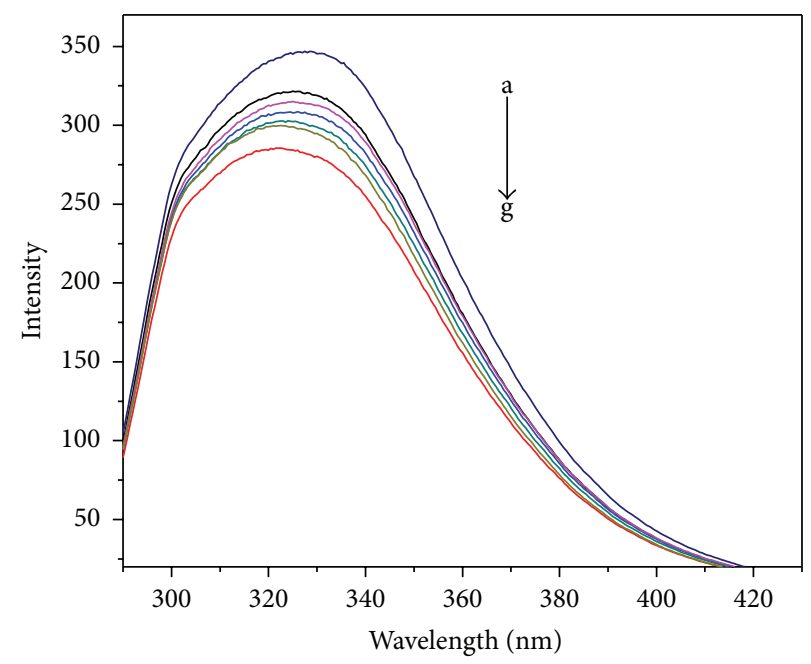

FIGURE 8: Fluorescence emission spectra of BSA with complex 1 in phosphate buffer. The concentration of complex varied from 0.0 to $3.2 \times 10^{-6} \mathrm{M} \mathrm{L}^{-1}$.

$280 \mathrm{~nm}$ and represented in Figures 8 and 9. As seen, with increasing the concentration of the complex, the fluorescence intensities of the proteins are repeatedly decreased. The fluorescence quenching is described by the Stern-Volmer relation [22]:

$$
\frac{F_{0}}{F}=1+K_{\text {sv }}[Q]
$$

where $F_{0}$ and $F$ indicate the fluorescence intensities in the absence and presence of quencher, respectively. $K_{\mathrm{sv}}$ is a linear Stern-Volmer quenching constant; $Q$ is the concentration of quencher. In case of fluorescence quenching of BSA, a linear plot between $I_{0}$ and $I$ against [complex] was obtained. $K_{\mathrm{sv}}$ calculated from the slope are $3.41 \mathrm{M}^{-1}(R=0.9836)$ and $3.58 \mathrm{M}^{-1}(R=0.9847)$ for complexes 1 and 2 , respectively. The binding constant values suggest that complexes strongly 


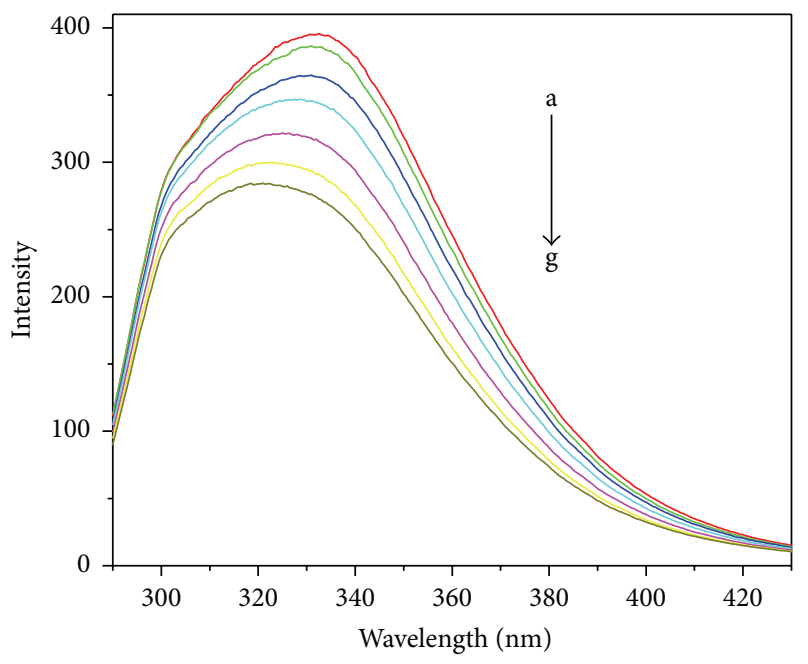

FIGURE 9: Fluorescence quenching spectra of BSA with complex 2 in phosphate buffer. The concentration of complex varied from 0.0 to $3.4 \times 10^{-6} \mathrm{M} \mathrm{L}^{-1}$.

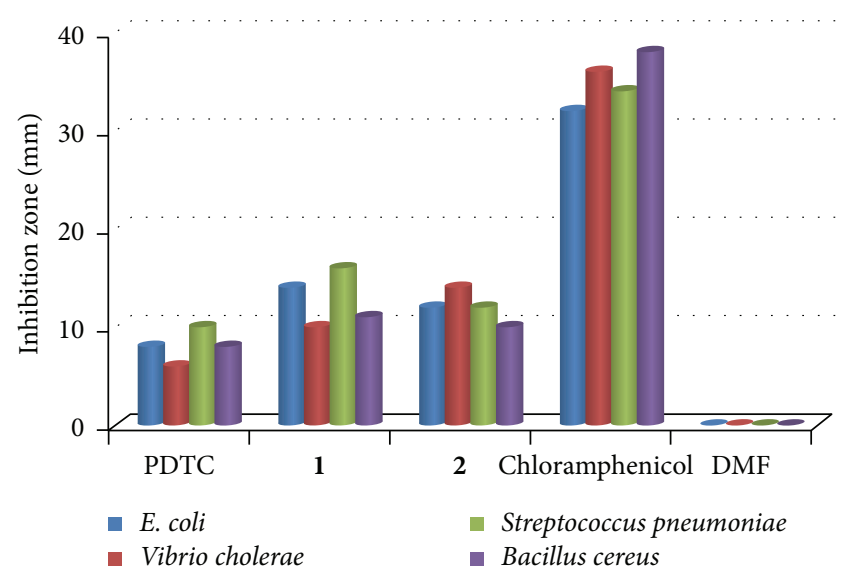

Figure 10: Antibacterial activity of ligand and its complexes (1 and 2).

bind to albumins. The linear Stern-Volmer plots indicate quenching mechanism either static or dynamic.

3.6. Antibacterial Activity. Determination of antimicrobial activity against specific pathogens is essential for proper therapy. The antibacterial activity was studied by agar disc diffusion method and comparison with standard antibiotic chloramphenicol is shown in Figure 10. From this experiment, it is contingent that complexes have more activity than free ligand $[23,24]$. The complexes are highly active due to increasing the delocalization of pi-electrons into the hole chelate ring, indicating increase in its lipophilicity. All the results indicate that chelation improved the antibacterial activity compared to the ligand.

\section{Conclusion}

Four coordinated square planars of Ni (II) and Pd (II) compound are synthesized and characterized by various spectroscopic tools. The compounds are strongly bound with BSA protein investigated by spectroscopic methods. The quenching constant value indicted that complexes have good binding with BSA through a static quenching mechanism. The biological data suggested that ligand and its metal (II) complexes displayed promising antibacterial activity compared to known antibiotic drug.

\section{Competing Interests}

The authors declare that there is no conflict of interests regarding the publication of this paper.

\section{Acknowledgments}

The authors are thankful to Professor Pabitra Chattopadhyay, Department of Chemistry, Burdwan University, Burdwan. The authors gratefully acknowledge the financial support from UGC Minor Research Project [F. no. PSW-142/14-15 (ERO)], India.

\section{References}

[1] H. P. S. Chauhan and U. P. Singh, "Synthetic, spectral, thermal and antimicrobial studies on some $b i s\left(N, N^{\prime}\right.$-dialkyldithiocarbamato) antimony(III) alkylenedithiophosphates," Applied Organometallic Chemistry, vol. 21, no. 10, pp. 880-889, 2007.

[2] S. Ahmad, A. A. Isab, and S. Ali, "Structural and mechanistic aspects of platinum anticancer agents: the structural factor," Transition Metal Chemistry, vol. 31, no. 8, pp. 1003-1016, 2006.

[3] L. J. Farrugia, F. J. Lawlor, and N. C. Norman, "Synthesis, characterization and single crystal X-ray analysis of chlorobis(N,N-dimethyldithiocarbamato-S,S')antimony(III)," Journal of the Chemical Society, Dalton Transaction, vol. 1, no. 7, pp. 11631171, 1995.

[4] S. S. Garje and V. K. Jain, "Coord. Synthesis, characterization and single crystal X-ray analysis of chlorobis $(N, N$-dimethyldithiocarbamato-S,S')antimony(III)," Chemical Review, vol. 236, no. 1, pp. 35-56, 2003.

[5] A. Gringeri, P. C. Keng, and R. F. Borch, "Diethyldithiocarbamate inhibition of murine bone marrow toxicity caused by cis-diamminedichloroplatinum(II) or diammine-(1,1-cyclobutanedicarboxylato)platinum(II)," Cancer Research, vol. 48, no. 20, pp. 5708-5712, 1988.

[6] H. P. S. Chauhan and J. Carpenter, "Synthesis, characterization and single crystal X-ray analysis of chlorobis $(N, N$ dimethyldithiocarbamato-S, $S^{\prime}$ )antimony(III)," Journal of Saudi Chemical Society, vol. 19, no. 4, pp. 417-422, 2015.

[7] C. A. Kavounis, S. C. Kokkou, P. J. Rentzeperis, and P. Karagiannidis, "Synthesis, characterization and single crystal X-ray analysis of chlorobis(N,N-dimethyldithiocarbamatoS,S')antimony(III)," Acta Crystallography Section B, vol. 38, no. 10, pp. 2686-2689, 1982.

[8] R. G. Kalkhambkar, G. M. Kulkarni, C. M. Kamanavalli, N. Premkumar, S. M. B. Asdaq, and C. M. Sun, "Synthesis and biological activities of some new fluorinated coumarins and 1aza coumarins," European Journal of Medicinal Chemistry, vol. 43, no. 10, pp. 2178-2188, 2008.

[9] I. V. Ukrainets, O. V. Gorokhova, and N. A. Jaradat, "Design, synthesis, characterization and evaluation of novel amides of 
pyridine derivative as antibacterial, anthelmintic and antiinflammatoty agents," Chemistry Compounds, vol. 42, no. 4, pp. 475-487, 2006.

[10] M. Usharani, E. Akila, P. Jayaseelan, and R. Rajavel, "Structural elucidation of newly synthesized potentially active binuclear Schiff base $\mathrm{Cu}(\mathrm{II}), \mathrm{Ni}(\mathrm{II}), \mathrm{Co}(\mathrm{II})$ and $\mathrm{Mn}(\mathrm{II})$ complexes using physicochemical methods," International Journal of Scientific \& Engineering Research, vol. 4, no. 7, pp. 1055-1064, 2013.

[11] C. Marzano, L. Ronconi, F. Chiara et al., "Gold(III)-dithiocarbamato anticancer agents: activity, toxicology and histopathological studies in rodents," International Journal of Cancer, vol. 129, no. 2, pp. 487-496, 2011.

[12] N. Raman, S. Sobha, and L. Mitu, "Synthesis, characterization, DNA interaction and pharmacological studies of substituted benzophenone derived Schiff base metal(II) complexes," Journal of Saudi Chemical Society, vol. 17, no. 2, pp. 151-159, 2013.

[13] S. M. Ben-Saber, A. A. Maihub, S. S. Hudere, and M. M. ElAjaily, "Complexation behavior of Schiff base toward transition metal ions," Microchemical Journal, vol. 81, no. 2, pp. 191-194, 2005.

[14] T. Yang, Z. Li, L. Wang, C. Guo, and Y. Sun, "Silver metallation of hen egg white lysozyme: $\mathrm{x}$-ray crystal structure and NMR studies," Langmuir, vol. 23, no. 21, pp. 10533-10538, 2007.

[15] G. Mandal, M. Bardhan, and T. Ganguly, "Fabrication of protein-conjugated silver sulfide nanorods in the bovine serum albumin solution," Journal of Physical Chemistry C, vol. 115, no. 43, pp. 20840-20848, 2011.

[16] S. G. de Almeida, J. L. Hubbard, and N. Farrell, "The Crystal Structure of a Novel Pt(II) Complex with 2-Hydroxy-6methylpyridine (Hmhp), trans-[PtCl2(dmso)(Hmhp)] $\mathrm{H}_{2} \mathrm{O}$," Inorganic Chimica Acta, vol. 193, no. 2, pp. 149-157, 1992.

[17] K. Nakamoto, Infrared and Raman Spectra of Inorganic and Coordination Compounds, John Wiley \& Sons, New York, NY, USA, 5th edition, 1997.

[18] G. Faraglia, S. Sitran, and D. Montagner, "Pyrrolidine dithiocarbamates of Pd(II)," Inorganica Chimica Acta, vol. 358, no. 4, pp. 971-980, 2005.

[19] A. Patra, B. Sen, S. Sarkar, A. Pandey, E. Zangrando, and P. Chattopadhyay, "Nickel(II) complexes with 2-(pyridin-3ylmethylsulfanyl)phenylamine and halide/pseudohalides: Synthesis, structural characterisation, interaction with CT-DNA and bovine serum albumin, and antibacterial activity," Polyhedron, vol. 51, no. 1, pp. 156-163, 2014.

[20] A. Patra, B. Mondal, B. Sen, E. Zangrando, and P. Chattopadhyay, "Nickel(II) complexes of $\mathrm{N}_{2} \mathrm{~S}_{2}$ donor set ligand and halide/pseudohalides: Synthesis, crystal structure, DNA and bovine/human serum albumin interaction," Journal of Chemical Sciences, vol. 127, no. 11, pp. 1883-1893, 2015.

[21] H. A. Benesi and J. H. Hildebrand, "A spectrophotometric investigation of the interaction of iodine with aromatic hydrocarbons," Journal of the American Chemical Society, vol. 71, no. 8, pp. 2703-2707, 1949.

[22] O. Stern and M. Volmer, "Über die Abklingzeit der Fluoreszenz," Zeitschrift für Physik, vol. 20, no. 1, pp. 183-188, 1919.

[23] J. Joseph, K. Nagashri, and G. Ayisha Bibin Rani, "Synthesis, characterization and antimicrobial activities of copper complexes derived from 4-aminoantipyrine derivatives," Journal of Saudi Chemical Society, vol. 17, no. 3, pp. 285-294, 2013.

[24] R. A. Sheikh, S. Shreaz, G. S. Sharma, L. A. Khan, and A. A. Hashmi, "Synthesis, characterization and antimicrobial screening of a novel organylborate ligand, potassium hydro(phthalyl)(salicylyl)borate and its $\mathrm{Co}(\mathrm{II}), \mathrm{Ni}(\mathrm{II})$, and $\mathrm{Cu}(\mathrm{II})$ complexes," Journal of Saudi Chemical Society, vol. 16, no. 4, pp. 353-361, 2012. 

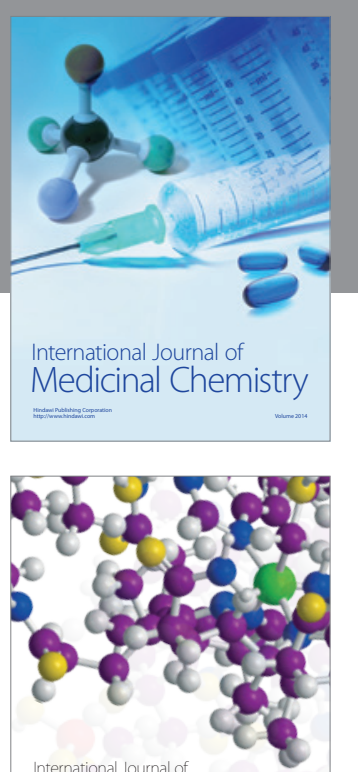

Carbohydrate Chemistry

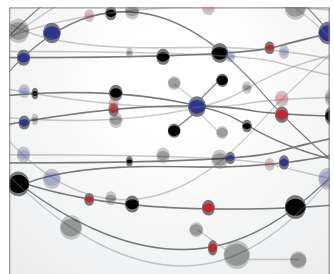

The Scientific World Journal
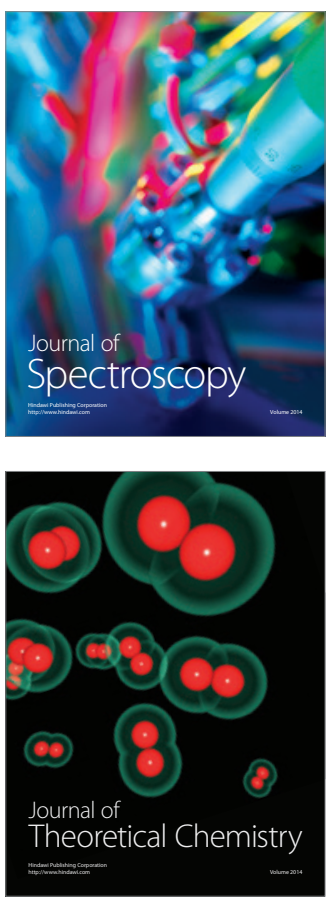
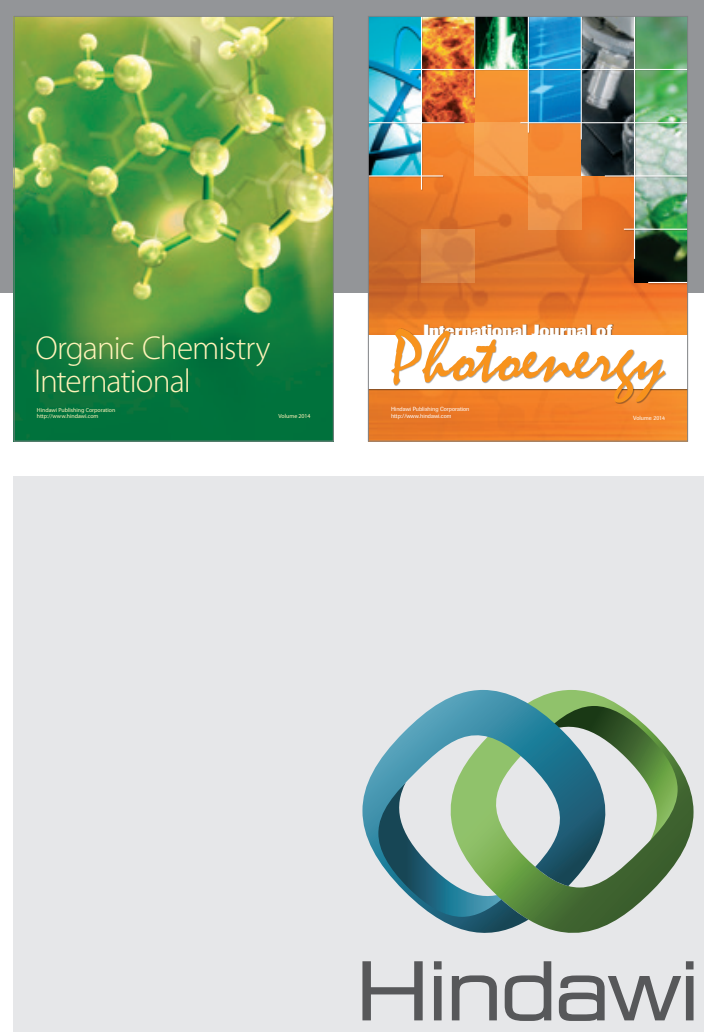

Submit your manuscripts at

http://www.hindawi.com

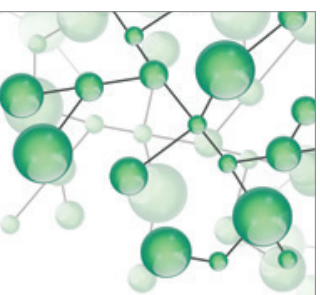

International Journal of

Inorganic Chemistry

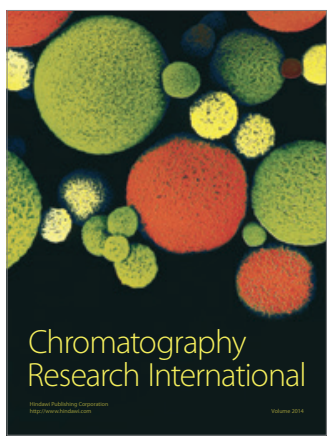

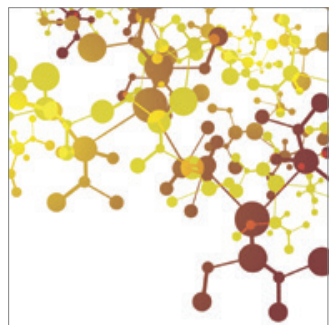

Applied Chemistry
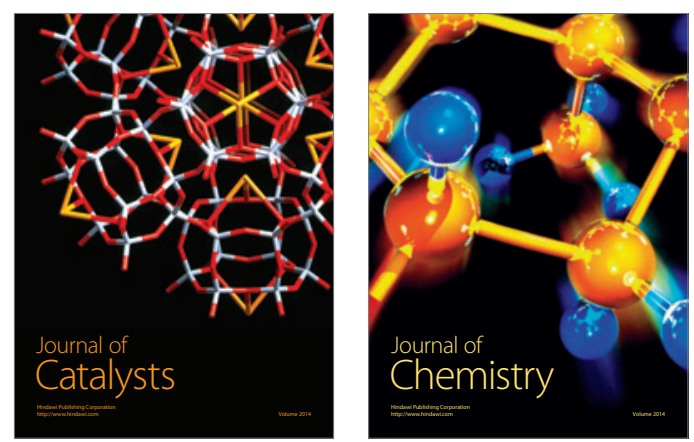
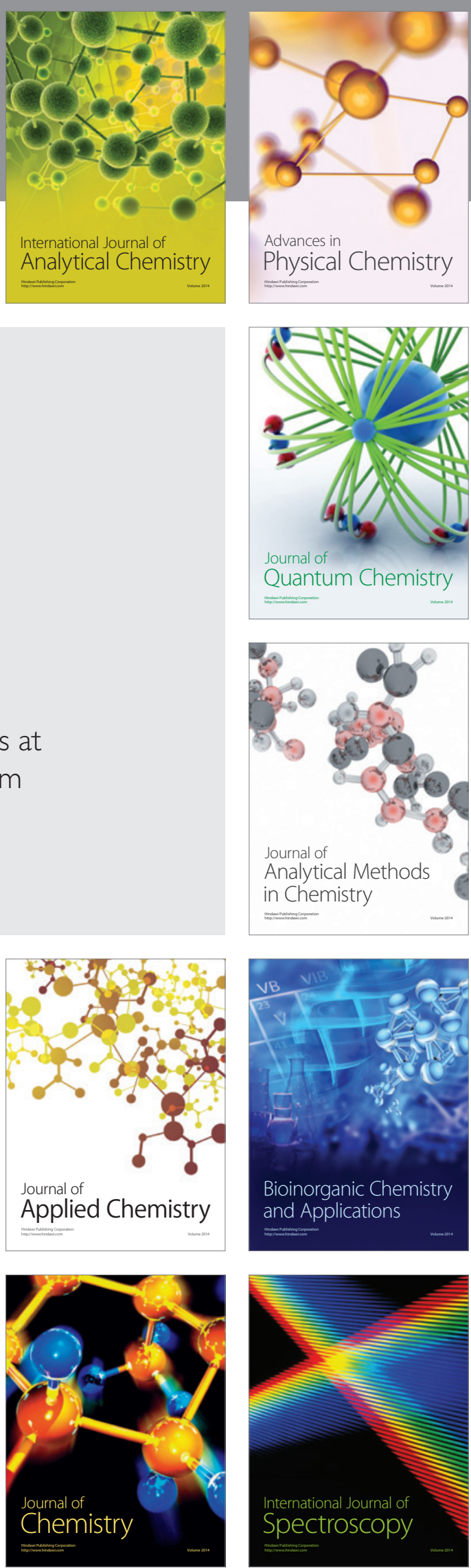